\title{
Patient preferences and factors related to the pre-procedure process at a large, urban county hospital
}

\author{
Lukejohn W. Day ${ }^{1,2,3^{*}}$, Michelle Nazareth ${ }^{3}$, Justin L. Sewell ${ }^{1,2,3}$ \\ ${ }^{1}$ Division of Gastroenterology, San Francisco General Hospital and Trauma Center, San Francisco, USA \\ ${ }^{2}$ GI Health Outcomes, Policy and Economics (HOPE) Research Program and Center for Innovation in Access and Quality, Depart- \\ ment of Medicine, University of California, San Francisco, USA \\ ${ }^{3}$ Gastroenterology Division, Department of Medicine, University of California, San Francisco, USA \\ Email: ${ }^{\text {lukejohn.day@ucsf.edu }}$
}

Received 8 November 2012; revised 8 December 2012; accepted 15 December 2012

\begin{abstract}
Background: Evaluation of the pre-procedural process prior to endoscopic procedures has never been conducted. Methods: Prospective cross-sectional, multilanguage survey was administered to outpatients undergoing endoscopy at a large, diverse county hospital that examined patients' pre-procedural preferences. Multivariate logistic regression was used to assess the relationship between patient preferences and several patient-related variables. Results: 128/156 outpatients completed the survey. The majority of respondents were female $(53.1 \%)$, did not speak English $(61.7 \%)$, were of Asian $(39.1 \%)$ or Hispanic $(29.7 \%)$ racial background, and had a mean age of $56.1 \pm 15.7$ years. Most patients underwent colonoscopy $(48.4 \%)$ with $90.6 \%$ of patients knowing the indication for their procedure. While waiting for their endoscopic procedure, $42.2 \%$ of patients preferred waiting in a gurney while $28.1 \%$ preferred to wait in a chair. In terms of being comfortable wearing a hospital gown and sitting in a chair or gurney in the pre-procedure area, mean patient anxiety scores were $5.2 \pm 3.3$ and $6.1 \pm 3.2$, respectively (scale of $1-10$ ). Race was associated with several pre-procedural patient preferences; Hispanics were less comfortable than Asians wearing a hospital gown while sitting in a chair with other patients prior to their procedure (OR $=0.3$, CI $0.1-1.0$ ) while Whites and African-Americans were less likely than Asians to prefer sitting in a chair as compared to a gurney before their procedure $(\mathrm{OR}=0.09$, CI $0.008-0.9$ and $\mathrm{OR}=0.07$, CI 0.007 0.8, respectively). Patients who had undergone a prior endoscopic procedure were less comfortable wearing a hospital gown and sitting in a chair $(\mathrm{OR}=0.3, \mathrm{CI}$ $0.1-0.7)$ or gurney $(\mathrm{OR}=0.4, \mathrm{CI} 0.2-1.0)$ in the pre-procedure area. Conclusion: A patient's race and
\end{abstract}

"Corresponding author. having had a prior endoscopic procedure were the most powerful predictors on pre-procedure patient preferences while sex, type of endoscopic procedure and patient knowledge of the indication for their procedure were not. Our study highlights the importance of patient preferences and factors involved in the pre procedure process at a large, diverse county hospital.

Keywords: Pre-Procedure Process; Quality; Endoscopy; Patient Preferences

\section{INTRODUCTION}

Nearly twenty million endoscopic procedures were performed in 2011 and this number has been dramatically increasing over the years. Personal preferences play a central role in patients' experiences at endoscopy centers and affect patients' willingness to return for subsequent endoscopic procedures. A number of patient preferences have been examined, but these preferences have solely focused on the procedure itself. Sex and training of the endoscopist [1-3], sedation received for their procedure [4], and the communication of post-endoscopy results [5] have been shown to influence patients' anxiety during the procedure and influence overall patient satisfaction. However, there is little literature examining the process and patient related factors that occur before an endoscopic procedure.

A number of factors are involved in endoscopy that occurs both before and after the procedure that may influence quality, efficiency and patient satisfaction. The pre-procedure process (i.e. the steps that occur while the patient is waiting for their procedure to begin) is an important part of a patient's experience at an endoscopy center. To date, scant information is available describing patient preferences with regards to the pre-procedural process. Available data is based on expert opinion or 
consensus (rather than quantitative data provided by patients), and focuses only on the architectural layout [6-8] and staffing $[9,10]$ of the pre-procedure space. This gap in the literature is critical to understand in order to be able to deliver the highest possible quality of care to patients.

To address this knowledge gap, we administered a survey to patients presenting for elective, ambulatory endoscopic procedures that investigated patient preferences related to the pre-procedure process, and examined factors related to these preferences.

\section{MATERIALS AND METHODS}

\subsection{Study Population and Setting}

San Francisco General Hospital and Trauma Center (SFGH) provides subspecialty care for the safety net healthcare system of the City and County of San Francisco, which includes multiple primary care clinics managed by the San Francisco Department of Public Health, and affiliated independent Federally Qualified Health Centers and Federally-Funded 300 (h) Grantee Centers. The SFGH GI Division receives 5300 referrals annually and performs over 3100 procedures per year on an ethnically diverse, underserved patient population.

The pre-procedure process at the SFGH endoscopy center is outlined as follows: After the patient has Registered for their procedure they are escorted from the waiting room to a separate pre-procedure area. This preprocedure area is a dedicated open room that consists of three gurneys which are separated by a series of partitions and curtains for patient privacy. After arriving at the pre-procedure area the patient is then escorted to a private bathroom and asked to change into a hospital gown and place their belongings into a separate bag. After changing into a hospital gown the patient is taken back to a gurney, asked to lie down, and then both a nursing and provider pre-assessment is performed, informed consent obtained, and an intravenous catheter is placed if moderate sedation is planned for their procedure. The patient will wait laying in a gurney until a procedure room and provider is available to perform their procedure. Once ready, the patient is then escorted on the gurney from the pre-procedure area to an available procedure room down the hall. Of note, directly adjacent to the pre-procedure area is the recovery area where at any given time up to three patients are recovering from their procedure(s). There is an open doorway connecting the pre-procedure and recovery areas.

\subsection{Study Design}

We conducted a prospective, cross-sectional survey focused on the pre-procedural process among patients who were scheduled for an elective outpatient endoscopic procedure at the SFGH endoscopy center. We used published expert opinions/consensus on the pre-procedure process to develop the survey $[7,8,10]$. Since $95 \%$ of our patients speak English, Spanish, or Cantonese, the survey was offered in these three languages. The initial survey was pilot tested on 45 consecutive patients (15 English, Spanish, and Cantonese speaking patients each) during May 2011 to assess for completeness and understandability by patients. The survey was then subsequently revised to its final version.

Patients undergoing an elective endoscopic procedure were invited to participate. LWD approached all outpatients in the pre-procedure room from June 1, 2011 to June 30, 2011 and invited patients to participate. In cases where a patient did not speak English an interpreter was used to invite patients to participate. As this was a quality improvement project only verbal consent was obtained.

\subsection{Data Collection}

The survey was divided into three parts. The first part of the survey asked questions relating to patient demographics (8 questions). The second part asked questions relating to patient preferences and the pre-procedure process (8 questions). Patient preferences solicited were: 1) privacy (private vs. non-private pre-procedure room); 2) method of waiting in the pre-procedure area (gurney vs. chair); 3) materials/media available (television, reading); 4) interaction with other patients; 5) proximity of the pre-procedure area to the recovery area and 6) how patients preferred to be escorted to the procedure room (gurney vs. walking). Lastly, patients were asked to rate their anxiety and how comfortable they felt sitting in either a chair or gurney wearing a hospital gown while waiting in the pre-procedure area with other patients. Patients were asked to respond to these three questions using a visual scale of 1 - 10 (1 = very uncomfortable/very anxious, 10 = very comfortable/not anxious).

\subsection{Statistical Analysis}

The mean and standard deviation were calculated for continuous data and proportions calculated for nominal data as it pertained to demographic information and patient preferences. Multivariate logistic regression models were built to assess the association between several patient-related independent variables of interest (sex, age, racial background, previous procedure, knowledge of the indication for the procedure, type of endoscopic procedure, and English as their primary language) and individual patient preferences. A statistically significant result was noted with $95 \%$ confidence interval (CI) and a p value $<0.05$. All calculations were performed on Stata 11.0 (Stata Corp ${ }^{\circledR}$, College Station, Texas). 


\subsection{Ethical Considerations}

This study was part of an ongoing quality improvement project aimed at evaluating our performance in the SFGH endoscopy center with respect to a patient's experience. Our goal was to design a pre-procedure area aimed at improving clinical care, patient safety and health care operations. Given our study was related to quality improvement, did not include testing the safety and efficacy of a drug or device in a human subject, and no personal health information was collected at any time formal institutional review was not required per the policy of the University of California San Francisco Committee on Human Research.

\section{RESULTS}

A total of 156 patients were approached for participation in the survey and 128 patients completed the survey (participation rate of $82.1 \%$ ). The mean age of patients was $56.1 \pm 15.7$ years with the majority being female (53.1\%). Racial and language diversity were represented in our study population; Asian (39.1\%) and Hispanic (29.7\%) were the most frequently reported racial background with $61.7 \%$ of patients not speaking English as their primary language. Colonoscopy (48.4\%) and upper endoscopy (21.1\%) were the most commonly performed procedures with $18.0 \%$ of patients undergoing dual endoscopy. More than half of the patients reported that this was their first endoscopic procedure. The vast majority of patients understood the indication for their procedure (90.6\%). See Table 1 for demographic and patient data.

\subsection{Patient Preferences and the Pre-Procedural Process}

A variety of patient preferences were considered with regards to the pre-procedure process and focused on patient location before a procedure, privacy, transport within the endoscopy center, media options and clothing attire before the procedure. While waiting for their endoscopic procedure $42.2 \%$ of patients preferred waiting in a gurney as opposed to $28.1 \%$ wanting to wait in a chair. Almost half $(44.5 \%)$ of patients preferred to wait in a private pre-procedure room with no other patients, and nearly as many (39.1\%) had no preference as to the privacy of the pre-procedure area. At the same time, observing other patients recovering from a procedure did not result in increased anxiety for most patients (64.1\%). The mean patient anxiety score while waiting for their procedure was $6.6 \pm 2.9$ (scale of 1 - 10). Slightly more patients would have preferred being transported to the procedure room in a gurney (45.3\%) rather than walking to the procedure room (30.5\%). However, most patients (48.4\%) preferred to begin the pre-procedure process in a
Table 1. Demographics of outpatients undergoing an endoscopic procedure who participated in the survey.

\begin{tabular}{|c|c|}
\hline Patient demographics & Number of patients (\%) \\
\hline Mean age, years $(S D)$ & $56.1 \pm 15.7$ \\
\hline \multicolumn{2}{|l|}{ Sex } \\
\hline Female & $68(53.1)$ \\
\hline Male & $55(43.0)$ \\
\hline No answer & $5(3.9)$ \\
\hline \multicolumn{2}{|l|}{ Race } \\
\hline Asian & $50(39.1)$ \\
\hline Hispanic & 38 (29.7) \\
\hline White & $20(15.6)$ \\
\hline African-American & $14(10.9)$ \\
\hline Other & $6(4.7)$ \\
\hline \multicolumn{2}{|l|}{ Endoscopic procedure } \\
\hline Colonoscopy & $62(48.4)$ \\
\hline Upper endoscopy & $27(21.1)$ \\
\hline Colonoscopy/upper endoscopy & $23(18.0)$ \\
\hline Flexible sigmoidoscopy & $4(3.1)$ \\
\hline Other & $1(0.8)$ \\
\hline No answer & $11(8.6)$ \\
\hline \multicolumn{2}{|l|}{ English as primary language } \\
\hline Yes & 49 (38.3) \\
\hline No & $79(61.7)$ \\
\hline \multicolumn{2}{|l|}{ Knowledge of procedure indication } \\
\hline Yes & $116(90.6)$ \\
\hline No & $7(5.5)$ \\
\hline No answer & $5(3.9)$ \\
\hline \multicolumn{2}{|l|}{ Previous endoscopic procedure } \\
\hline Yes & $50(39.1)$ \\
\hline No & $76(59.4)$ \\
\hline No answer & $2(1.6)$ \\
\hline
\end{tabular}

designated pre-procedure area, rather than being taken directly to the procedure room. With regards to media being available within the pre-procedure area most patients preferred being able to watch television while waiting for their procedure (47.7\%) while slightly less patients wanted reading material present $(43.0 \%)$. With respect to clothing attire, mean patient comfort scores were $5.2 \pm 3.3$ and $6.1 \pm 3.2$ for wearing a hospital gown and sitting on a chair or laying in a gurney, respectively (scale of 1 - 10). See Table 2 for summary of patient preferences.

\subsection{Predictors of Pre-Procedural Patient Preferences}

Several predictors were analyzed with respect to patient preferences and the pre-procedural process (Table 3). A patient's racial background and having had a prior endoscopic procedure were the most powerful predictors of 
Table 2. Patient preferences related to the pre-procedure process.

\begin{tabular}{|c|c|}
\hline $\begin{array}{l}\text { Patient preferences regarding } \\
\text { the pre-procedure process }\end{array}$ & $\begin{array}{c}\text { Number of } \\
\text { patients (\%) }\end{array}$ \\
\hline \multicolumn{2}{|l|}{ Do you prefer to wait in a chair or gurney? ${ }^{\mathrm{a}}$} \\
\hline Gurney & $54(42.2)$ \\
\hline Chair & $36(28.1)$ \\
\hline No preference & 37 (28.9) \\
\hline No answer & $1(0.8)$ \\
\hline \multicolumn{2}{|c|}{ Do you prefer to wait in a private or shared room $?^{\mathrm{a}}$} \\
\hline Private room & $57(44.5)$ \\
\hline Shared room & $13(10.2)$ \\
\hline No preference & $50(39.1)$ \\
\hline No answer & $8(6.3)$ \\
\hline \multicolumn{2}{|l|}{ Would you have liked reading material? ${ }^{\mathrm{a}}$} \\
\hline Yes & $55(43.0)$ \\
\hline No & $60(46.9)$ \\
\hline No answer & $13(10.2)$ \\
\hline \multicolumn{2}{|l|}{ Would you have liked to watch television? ${ }^{\mathrm{a}}$} \\
\hline Yes & $61(47.7)$ \\
\hline No & $55(43.0)$ \\
\hline No preference & $1(0.8)$ \\
\hline No answer & $11(8.6)$ \\
\hline \multicolumn{2}{|l|}{$\begin{array}{l}\text { Would you have preferred to have been taken } \\
\text { directly to the procedure room? }\end{array}$} \\
\hline Yes & $48(37.5)$ \\
\hline No & $62(48.4)$ \\
\hline No preference & $3(2.3)$ \\
\hline No answer & $15(11.7)$ \\
\hline \multicolumn{2}{|c|}{$\begin{array}{l}\text { Do you prefer to walk or be escorted on a gurney } \\
\text { to the procedure room? }\end{array}$} \\
\hline Gurney & $58(45.3)$ \\
\hline Walk & 39 (30.5) \\
\hline No preference & $23(18.0)$ \\
\hline No answer & $8(6.3)$ \\
\hline \multicolumn{2}{|c|}{$\begin{array}{l}\text { Do you feel more anxious observing other patients } \\
\text { who have just completed their procedure? }\end{array}$} \\
\hline Yes & 24 (18.8) \\
\hline No & $82(64.1)$ \\
\hline No answer & $22(17.2)$ \\
\hline \multicolumn{2}{|l|}{$\begin{array}{l}\text { Would you have preferred your procedure } \\
\text { outside of the hospital? }\end{array}$} \\
\hline Yes & $8(6.3)$ \\
\hline No & $112(87.5)$ \\
\hline No answer & $8(6.3)$ \\
\hline
\end{tabular}

${ }^{a}$ Pertains to patient waiting in the pre-procedure area.

pre-procedure patient preferences. Hispanics were less comfortable than Asians wearing a hospital gown while sitting in a chair in the pre-procedure area $(\mathrm{OR}=0.3$, CI $0.1-1.0, \mathrm{p}=0.04)$. Whites and African-Americans were less likely than Asians to want to sit in a chair as com-
Table 3. Independent predictors of pre-procedure patient preferences.

\begin{tabular}{|c|c|c|}
\hline Patient preferences & $\begin{array}{l}\text { Odds ratio } \\
\text { (95\% CI) }\end{array}$ & p-value \\
\hline \multicolumn{3}{|c|}{$\begin{array}{l}\text { Patients prefer a private pre-procedure } \\
\text { room. }\end{array}$} \\
\hline \multicolumn{3}{|l|}{ English as primary language } \\
\hline Yes & $0.1(0.01-0.7)$ & 0.02 \\
\hline \multicolumn{3}{|c|}{$\begin{array}{l}\text { Patients prefer to wait in a chair versus a } \\
\text { gurney. }\end{array}$} \\
\hline \multicolumn{3}{|l|}{ Race $^{a}$} \\
\hline Asian & 1.0 & \\
\hline White & $0.09(0.008-0.9)$ & 0.04 \\
\hline African-American & $0.07(0.007-0.8)$ & 0.03 \\
\hline \multicolumn{3}{|c|}{$\begin{array}{l}\text { Patients prefer sitting in a chair wearing a } \\
\text { hospital gown prior to their procedure. }\end{array}$} \\
\hline \multicolumn{3}{|l|}{ Race $^{\mathrm{a}}$} \\
\hline Asian & 1.0 & \\
\hline Hispanic & $0.3(0.1-1.0)$ & 0.04 \\
\hline \multicolumn{3}{|l|}{ Prior Procedure } \\
\hline Yes & $0.3(0.1-0.7)$ & 0.01 \\
\hline \multicolumn{3}{|c|}{$\begin{array}{l}\text { Patients prefer laying in a gurney wearing } \\
\text { a hospital gown prior to their procedure. }\end{array}$} \\
\hline \multicolumn{3}{|l|}{ Prior procedure } \\
\hline Yes & $0.4(0.2-1.0)$ & 0.05 \\
\hline \multicolumn{3}{|c|}{$\begin{array}{l}\text { Patients prefer to walk versus being taken } \\
\text { on a gurney to the procedure room. }\end{array}$} \\
\hline \multicolumn{3}{|l|}{ Race $^{a}$} \\
\hline Asian & 1.0 & \\
\hline Hispanic & $0.2(0.07-0.9)$ & 0.03 \\
\hline \multicolumn{3}{|c|}{$\begin{array}{l}\text { Patients prefer to be taken directly to the } \\
\text { procedure room versus waiting in a } \\
\text { pre-procedure area. }\end{array}$} \\
\hline \multicolumn{3}{|l|}{ Age } \\
\hline $20-30$ & 1.0 & \\
\hline $61-70$ & $9.5(1.0-90.2)$ & 0.05 \\
\hline \multicolumn{3}{|l|}{ Race $^{\mathrm{a}}$} \\
\hline Asian & 1.0 & \\
\hline White & $0.2(0.06-0.9)$ & 0.04 \\
\hline
\end{tabular}

Note: An adjusted analysis was performed on each patient preference controlling for the following predictors: age group, sex, race, history of previous procedure, knowledge of the indication for the procedure, type of endoscopic procedure, and English as their primary language. Only statistically significant independent predictors are reported. CI (Confidence interval). ${ }^{a}$ Given that Asians were the most prevalent racial group they were selected as the reference group.

pared to a gurney in the pre-procedure area $(\mathrm{OR}=0.09$, CI $0.008-0.9, \mathrm{p}=0.04$ and $\mathrm{OR}=0.07$, CI $0.007-0.8, \mathrm{p}$ $=0.03$ respectively). Also, Whites were less likely than Asians to want to be taken directly to the procedure room rather than wait in a pre-procedure area $(\mathrm{OR}=0.2$, CI $0.06-0.9, \mathrm{p}=0.04$ ). Patients who had undergone a prior endoscopic procedure were less comfortable wearing a hospital gown and sitting in a chair $(\mathrm{OR}=0.3$, CI 0.1 $0.7, \mathrm{p}=0.01)$ or gurney $(\mathrm{OR}=0.4$, CI $0.2-1.0, \mathrm{p}=0.05)$ 
in a pre-procedure area with other patients. Finally, English speakers were less likely to prefer a private preprocedure room $(\mathrm{OR}=0.1$, CI $0.01-0.7, \mathrm{p}=0.02)$. Sex, type of endoscopic procedure and patient knowledge as to the indication for their procedure were not associated with any pre-procedural patient preferences.

\section{DISCUSSION}

To our knowledge, this study is the first to critically examine the pre-procedural process in an outpatient endoscopy center at a large, diverse county hospital. A number of strong patient preferences with respect to privacy, transport within the endoscopy center, media options, location of the pre-procedure area and clothing attire before the procedure were evident in our patient population. Additionally, patient's race and having had a prior endoscopic procedure were the most powerful predictors of pre-procedure patient preferences while sex, primary language and patient knowledge of the indication for their procedure were less important. Knowledge of patient's preferences regarding the pre-procedure process helps inform clinical decision making with respect to efficiency and optimizing patient flow, and helps to balance these considerations with patient satisfaction.

The pre-procedure process is integral to a patient's overall satisfaction with their experience at an endoscopy center and can affect their decision to return, as well as shape their perception of the endoscopic procedure itself. It is for this reason that understanding patient's perceptions and factors that affect it are critical; however there is a dearth of research on this important aspect of endoscopy. Existing studies of the pre-procedure process have centered solely on enhancing efficiency by maximizing the number of patients that can be accommodated, improving work flow, and increasing productivity and utilization $[7,8,11,12]$. Implementation of these data may help maximize endoscopic efficiency, but this may not necessarily improve patient experience, and actually has the potential to harm it. Accordingly, scant recommendations on the pre-procedure process have been put forth, with none being evidence based, and all relying on provider perception and experience.

A critical element at enhancing a patient's experience at the endoscopy center is to reduce their anxiety. Patient anxiety plays an important role in the safety and success of endoscopic procedures. Higher levels of anxiety can lead to physiologic changes such as increased blood pressure and heart rate which may lead to more sedating medications used for patients, increased procedure times, and increased patient discomfort making it more difficult to perform a thorough examination [13-15]. Such anxiety not only can affect specific aspects of the procedure but also a patient's willingness to return in the future and how they communicate such an experience to others. Addressing such anxiety before endoscopy is essential. Pre-procedure teaching [16], relaxation techniques [16] and music [16-18] have been shown to dramatically reduce patient anxiety during a procedure as well as some physiologic parameters, yet none of these interventions have been studied in the pre-procedure setting. We examined factors that are an essential part of the pre-procedure process that could potentially be used to reduce anxiety for patients waiting for their endoscopy. We discovered that specific forms of media, similar to music from previous studies, are important to patients during their endoscopy experience and exposure to it may help to minimize feelings of anxiety. While our patients were not more anxious seeing other patients recovering from an endoscopy, they preferred to have their own individual pre-procedure room indicating that privacy is also important. Many have argued that creating a hospital-like environment before endoscopy where patients change directly into a hospital gown, lay in gurneys, and are escorted to their procedure in a gurney may elevate feelings of anxiety and that such settings be modified [8] or even discouraged. However, our study demonstrates that many patients prefer a more hospital-based experience from the moment they arrive at the endoscopy center. All of these preferences need to be taken into consideration when creating the process flow and pre-procedure environment as it can have an effect on patient anxiety and ultimately the procedure. Our information is crucial in that it not only can be incorporated into one's practice to improve patient satisfaction but can also be used to help reinforce and support proposed efficiency models at endoscopy centers. Additionally, as patient satisfaction becomes tied to reimbursements in the future our data can help to potentially aid in achieving such outcomes.

Interestingly, we found a number of predictors related to patient pre-procedure preferences; specifically patient race was by far the most dominant predictor. Racial and cultural differences have been observed in colorectal cancer screening choices and programs [19], and it is not surprising that such differences would also be noted in patient preferences while waiting for an endoscopy. Differences observed between English and non-English speakers in our study are likewise probably due to cultural beliefs from our diverse patient population. All of these differences need to be considered when designing and organizing the pre-procedure area and flow as it may affect each group differently and thus the overall experience and future willingness for some patients to return for a procedure. Moreover, we also noted that patients who had undergone a previous endoscopic procedure were less willing to sit in a chair or lay in a gurney while wearing a hospital gown while waiting for their procedure. Perhaps this group of patients had a less than fa- 
vorable experience during their previous endoscopy or not knowing what to expect prior to a procedure makes patients more willing to accept a specific situation; both of which could shape this particular group of patient's preferences.

There were several limitations to our study. First, our study population consisted mostly of immigrant, nonEnglish speaking individuals, and may not be generalizable to all endoscopy center populations across the US. Second, our survey has not been validated by previous research, however this area of research is sparse and no validated survey is currently available. Third, we subjecttively assessed patient's anxiety prior to their procedure and did not correlate it with objective findings such as vital signs or amount of sedation used during the procedure. Fourth, previous studies on patient satisfaction during surgery [20] have found that predictors of patient satisfaction include a number of factors such as perceived length of stay which we did not account for in our study. Lastly, we did not obtain data on patient's comorbidities, including anxiety disorders or patient's taking ant-anxiety medications, which could potentially influence patient's preferences prior to endoscopy.

In summary, we conducted a comprehensive evaluation of the pre-procedure process at a large, diverse county hospital. The pre-procedure process is crucial at reducing anxiety for patients, shaping the patient's overall experience at the endoscopy center and possibly affecting future decisions about returning or having an endoscopy. We discovered a number of patient preferences relating to the method of waiting before a procedure, privacy, transport within the endoscopy center, media options and clothing attire before the procedure. Patient race and having had a prior procedure strongly affected these preferences. This information will not only help endoscopy centers in improving efficiency and patient flow, but when taken into consideration can lead to the creation of a more patient-centered environment.

\section{REFERENCES}

[1] Fidler, H., Hartnett A., Cheng, M.K., Derbyshire, I. and Sheil, M. (2000) Sex and familiarity of colonoscopists: Patient preferences. Endoscopy, 32, 481-482. doi:10.1055/s-2000-645

[2] Varadarajulu, S., Petruff, C. and Ramsey, W.H. (2002) Patient preferences for gender of endoscopists. Gastrointestinal Endoscopy, 56, 170-173. doi:10.1016/S0016-5107(02)70173-9

[3] Schneider, A., Kanagarajan, N., Anjelly, D., Reynolds, J.C. and Ahmad, A. (2009) Importance of gender, socioeconomic status, and history of abuse on patient preference for endoscopist. American Journal of Gastroenterology, 104, 340-348. doi:10.1038/ajg.2008.96

[4] Subramanian, S., Liangpunsakul, S. and Rex, D.K. (2005)
Preprocedure patient values regarding sedation for colonoscopy. Journal of Clinical Gastroenterol, 39, 516-519. doi:10.1097/01.mcg.0000165667.79530.44

[5] Chartier, L., Arthurs, E. and Sewitch, M.J. (2009) Patient satisfaction with colonoscopy: A literature review and pilot study. Canadian Journal of Gastroenterology, 23, 203-209.

[6] Kowalski, T., Edmundowicz, S. and Vacante, N. (2004) Endoscopy unit form and function. Gastrointestinal Endoscopy Clinics of North America, 14, 657-666. doi:10.1016/j.giec.2004.04.006

[7] Marasco, J.A. and Marasco, R.F. (2002) Designing the ambulatory endoscopy center. Gastrointestinal Endoscopy Clinics of North America, 12, 185-204. doi:10.1016/S1052-5157(01)00002-2

[8] Petersen, B.T. (2006) Promoting efficiency in gastrointestinal endoscopy. Gastrointestinal Endoscopy Clinics of North America, 16, 671-685. doi:10.1016/j.giec.2006.08.011

[9] SGNA Position Statement (2002) Minimal registered nurse staffing for patient care in the gastrointestinal endoscopy unit. Gastroenterology Nursing, 25, 269-270.

[10] Al-Kawas, F.H. and Brugge, W.R. (2008) Report of the first endoscopy unit directors meeting: March 29-30, 2008, Georgetown University Conference Center, Washington DC. Gastrointestinal Endoscopy, 68, 1153-1157. doi:10.1016/j.gie.2008.07.050

[11] Harewood, G.C., Chrysostomou, K., Himy, N. and Leong, W.L. (2008) A "time-and-motion" study of endoscopic practice: Strategies to enhance efficiency. Gastrointestinal Endoscopy, 68, 1043-1050. doi:10.1016/j.gie.2008.03.1116

[12] Johanson, J.F., Overholt, B.F. and Frakes, J.T. (1999) Characteristics of best gastroenterology practices. American Journal of Gastroenterology, 94, 2519-2530. doi:10.1111/j.1572-0241.1999.01387.x

[13] Brandt, L.J. (2001) Patients' attitudes and apprehensions about endoscopy: How to calm troubled waters. American Journal of Gastroenterology, 96, 280-284.

[14] Johnson, J.E., Morrissey, J.F. and Leventhal, H. (1973) Psychological preparation for an endoscopic examination. Gastrointestinal Endoscopy, 19, 180-182. doi:10.1016/S0016-5107(73)73995-X

[15] Hayes, A., Buffum, M., Lanier, E., Rodahl, E. and Sasso, C. (2003) A music intervention to reduce anxiety prior to gastrointestinal procedures. Gastroenterology Nursing, 26, 145-149. doi:10.1097/00001610-200307000-00002

[16] Salmore, R.G. and Nelson, J.P. (2000) The effect of preprocedure teaching, relaxation instruction, and music on anxiety as measured by blood pressures in an outpatient gastrointestinal endoscopy laboratory. Gastroenterology Nursing, 23, 102-110. doi:10.1097/00001610-200005000-00003

[17] Bechtold, M.L., Puli, S.R., Othman, M.O., Bartalos, C.R., Marshall, J.B. and Roy, P.K. (2009) Effect of music on patients undergoing colonoscopy: A meta-analysis of randomized controlled trials. Digestive Diseases and Sciences, 54, 19-24. doi:10.1007/s10620-008-0312-0 
[18] El-Hassan, H., McKeown, K. and Muller, A.F. (2009) Clinical trial: Music reduces anxiety levels in patients attending for endoscopy. Alimentary Pharmacology \& Therapeutics, 30, 718-724. doi:10.1111/j.1365-2036.2009.04091.x

[19] Inadomi, J.M., Vijan, S., Janz, N.K., et al. (2012) Adherence to colorectal cancer screening: a randomized clinical trial of competing strategies. Archives of Internal Medicine, 172, 575-582. doi:10.1001/archinternmed.2012.332

[20] Schoenfelder, T., Klewer, J. and Kugler J. (2010) Factors associated with patient satisfaction in surgery: The role of patients' perceptions of received care, visit characteristics, and demographic variables. Journal of Surgical Research, 164, e53-e59. doi:10.1016/j.jss.2010.08.001 